Check for updates

Cite this: Mater. Chem. Front. 2019, 3, 50

Received 5th September 2018, Accepted 22nd October 2018

DOI: $10.1039 / c 8 q m 00454 d$

rsc.li/frontiers-materials

\title{
An o-phthalimide-based multistimuli-responsive aggregation-induced emission (AIE) system $\uparrow$
}

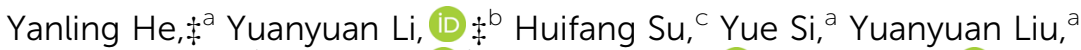 \\ Qiuchen Peng, ${ }^{\mathrm{ab}}$ Juan He, (D) ${ }^{\mathrm{b}}$ Hongwei Hou (D) ${ }^{\mathrm{a}}$ and Kai Li (D) ${ }^{\mathrm{a}}$
}

\begin{abstract}
Aggregation-induced emission luminogens (AlEgens) have been widely used in the development of functional materials due to their excellent luminescence properties in the solid state. The development of new AlEgens is of great significance. In this work, a novel o-phthalimide-based AlEgen of 2,3-diphenylquinoxaline-6,7-dicarboimide (2) is reported, which exhibited multifunctional sensing applications. Interestingly, compound $\mathbf{2}$ exhibited ultrafast photo-response properties upon UV light irradiation in both the dissolved state and solid state, which was attributed to a unique photo-induced rearrangement reaction. This property of $\mathbf{2}$ makes it suitable for UV sensing and photo-patterning materials with a significant fluorescence change. Meanwhile, based on the highly specific interaction

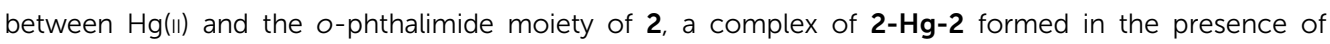
0.5 equiv. $\mathrm{Hg}(\Perp)$, resulting in a strong fluorescence change of $\mathbf{2}$. The active hydrogen in the o-phthalimide moiety also makes the fluorescence of $\mathbf{2}$ sensitive to the $\mathrm{pH}$ of aqueous solutions. Due to these characteristics, 2 was successfully used in the detection of UV light, $\mathrm{Hg}(॥)$ and the $\mathrm{pH}$ of aqueous solutions, in which $\mathbf{2}$ exhibited satisfactory detection performance.
\end{abstract}

\section{Introduction}

Luminogens with aggregation-induced emission (AIE) properties have attracted considerable attention because of their promising applications in the fields of chemosensors, bioimaging, organic light-emitting diodes (OLEDs), smart materials, etc. ${ }^{1}$ Unlike the traditional aggregation-caused quenching (ACQ) luminogens, whose luminescence in dispersed states is much stronger than that in aggregated states, AIE luminogens (AIEgens) exhibit intense luminescence in aggregated states such as in concentrated solutions and solid states. ${ }^{2}$ This characteristic makes AIEgens suitable for luminescent chemosensors because most of the detections need to be performed in aqueous solutions where organic sensors usually have poor solubility and exist in an aggregated state. ${ }^{3}$

To date, a series of AIEgen-based luminescent chemosensors have been reported with excellent performances for the

\footnotetext{
${ }^{a}$ College of Chemistry and Molecular Engineering, Zhengzhou University, Zhengzhou, 450001, P. R. China. E-mail: houhongw@zzu.edu.cn, likai@zzu.edu.cn ${ }^{b}$ College of Chemistry, Chemical and Environmental Engineering, Henan University of Technology, Zhengzhou, 450001, P. R. China. E-mail: yuanyuanli@haut.edu.cn ${ }^{c}$ Department of Osteology, The First Affiliated Hospital of Zhengzhou University, Zhengzhou, 450001, P. R. China

$\dagger$ Electronic supplementary information (ESI) available: Selected spectra and data referred to in the paper; detailed crystal data and structure refinement for $\mathbf{2}$. CCDC 1859465. For ESI and crystallographic data in CIF or other electronic format see DOI: $10.1039 / \mathrm{c} 8 q \mathrm{~mm} 00454 \mathrm{~d}$

¥ Y. He and Y. Li contributed equally to this work.
}

detection of different analytes such as reactive oxygen species (ROS), metal ions, toxic substances, amino acids, $\mathrm{pH}$, explosives and so on, which exhibit excellent performances. ${ }^{4}$ However, most of the reported chemosensors exhibit only singular sensing capability, and AIEgens with multifunctional sensing applications are still rare. Meanwhile, it is noticed that most of these reported chemosensors are designed based on a limited number of classic AIEgens such as tetraphenylethene (TPE), hexaphenylsilole (HPS), tetraphenylpyrazine (TPP), salicylaldehyde azine (SAA), and (2-hydroxyphenyl)benzothiazole (HBT), etc. ${ }^{5}$ The development of new AIEgens for luminescent chemosensors is still of great interest and importance.

In this work, an $o$-phthalimide moiety was introduced for the preparation of a new AIE system and a novel AIEgen of 2,3-diphenylquinoxaline-6,7-dicarboimide (2) was facilely synthesized via two-step reactions involving commercially available materials (Scheme 1). 2 exhibits a typical AIE characteristic due to the restriction of intramolecular rotation (RIR) mechanism. The $o$-phthalimide moiety of $\mathbf{2}$ endows it with a multifunctional sensing performance. The electron-withdrawing ability properties

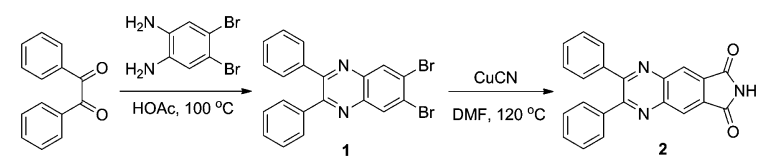

Scheme 1 Synthesis of 1 and 2 . 
of $o$-phthalimide activated the phenyl group in 2. Upon UV light irradiation, 2 turned into 3 via a unique photo-induced rearrangement reaction within $5 \mathrm{~s}$, along with a remarkable fluorescence change from blue to green, which makes 2 suitable for monitoring ultraviolet radiation. Meanwhile, based on the highly specific interaction of $\mathrm{Hg}$ (II) with $o$-phthalimide, 2 was successfully used in the detection of $\mathrm{Hg}$ (II) in aqueous solutions with good selectivity and sensitivity. The active hydrogen in the $o$-phthalimide moiety also makes the fluorescence of 2 sensitive to the $\mathrm{pH}$ of the aqueous solution. Under alkaline conditions, the deprotonation endows 2 with stronger and blue-shifted luminescence compared to that under acidic conditions, which makes it suitable for detecting the $\mathrm{pH}$ of an aqueous solution.

\section{Experimental section}

\subsection{Reagents}

Unless otherwise stated, all materials used in this work are commercially available without further purification. 4,5-Dibromo1,2-benzenediamine was purchased from AIEgen Biotech Co., Limited, Hong Kong. Benzil, copper(I) cyanide, and poly(ethyleneglycol) (M.W. 6000) were purchased from J\&K Chemical Co. Beijing, China. All the other materials such as organic solvents, metal salts, acids and alkalis were purchased from Sinopharm Chemicals Beijing Co. Beijing, China. Analytical grade organic solvents and doubly distilled deionized water were used throughout the experiments. The solutions of all metal ions were prepared from their perchlorate salts or nitrate salts of analytical grade. $\mathrm{Fe}(\mathrm{II})$ solution was prepared from $\left(\mathrm{NH}_{4}\right)_{2} \mathrm{Fe}\left(\mathrm{SO}_{4}\right)_{2}$. $10 \mathrm{mmol} \mathrm{L}{ }^{-1}$ phosphate buffer solutions (PBS) with different $\mathrm{pH}$ values were prepared using different ratios of phosphoric acid, sodium dihydrogen phosphate and sodium hydroxide. A $10 \mathrm{mmol} \mathrm{L}^{-1}$ Tris solution of $\mathrm{pH} 7.0$ was prepared using tris(hydroxymethyl)aminomethane and moderate perchloric acid. The $\mathrm{pH}$ values of the buffer solutions were detected using a $\mathrm{pH}$ meter at room temperature.

\subsection{Apparatus}

Absorption spectra were obtained on a JASCO V-750 UV-Vis spectrometer. Fluorescence spectra were obtained on a JASCO FP-8300 spectrometer. All pH values are detected using a METTLER-TOLEDO FE20/EL20 pH meter. The nuclear magnetic resonance (NMR) spectra were recorded on a Bruker 400 Avance NMR spectrometer operated at $400 \mathrm{MHz}$. ESI-MS spectra were obtained on Agilent Technologies 6420 triple quadruopole LC/MS apparatus without using the LC part. Dynamic Light Scattering (DLS) experiments were performed using a NanoPlus-3 dynamic light scattering particle size/zeta potential analyzer. Single crystal X-ray diffraction analysis was performed on a Rigaku Saturn 724 CCD diffractometer with Mo $\mathrm{K} \alpha$ radiation $(\lambda=0.71073 \AA)$ at room temperature. Light with different wavelengths was produced by a CEL-HXF300/CELHXUV300 xenon light source with different optical filters. High performance liquid chromatography (HPLC) analysis was performed using JASCO LC-4000 HPLC apparatus with a fluorescence detector and an absorbance detector. The power density of light was detected using a CEL-NP200 light power meter. The photos and videos were taken using a Nikon D5500 camera.

\subsection{Syntheses}

The synthetic routes of the new compounds are shown in Scheme 1. Detailed synthetic procedures are shown below and the characterization data of the new compounds are shown in the ESI. $\dagger$

2,3-Diphenyl-6,7-dibromoquinoxaline (1). 1,2-Diphenyl-1,2ethanedione ( $5 \mathrm{mmol}, 1.05 \mathrm{~g}$ ) and benzil ( $5 \mathrm{mmol}, 1.30 \mathrm{~g}$ ) are mixed in $10 \mathrm{~mL}$ acetic acid. The mixture was stirred and heated to $110{ }^{\circ} \mathrm{C}$ for $3 \mathrm{~h}$. After cooling to room temperature, a white precipitate was formed. The precipitate was filtrated and washed using $10 \mathrm{~mL}$ acetic acid three times. After being dried under reduced pressure, compound $\mathbf{1}$ was obtained as a white powder (1.85 g, yield 84\%). ${ }^{1} \mathrm{H}$ NMR $\left(400 \mathrm{MHz}, \mathrm{CDCl}_{3}\right) \delta(\mathrm{ppm})$ : $8.49(\mathrm{~s}, 1 \mathrm{H}), 7.50(\mathrm{~d}, J=4.0 \mathrm{~Hz}, 2 \mathrm{H}), 7.39$ (t, $J=4.0 \mathrm{~Hz}, 1 \mathrm{H}), 7.34$ $(\mathrm{t}, J=4.0 \mathrm{~Hz}, 2 \mathrm{H}) .{ }^{13} \mathrm{C} \mathrm{NMR}\left(100 \mathrm{MHz}, \mathrm{CDCl}_{3}\right) \delta(\mathrm{ppm}): 154.56$, 140.42, 138.40, 133.23, 129.82, 129.33, 128.37, 126.43. ESI-MS spectrometry: $m / z$ calculated for $[\mathrm{M}+\mathrm{H}]^{+}$: 438.94; found: 438.96.

2,3-Diphenylquinoxaline-6,7-dicarboimide (2). Compound 1 ( $1 \mathrm{mmol}, 0.44 \mathrm{~g}$ ) and copper(I) cyanide ( $5 \mathrm{mmol}, 0.45 \mathrm{~g}$ ) were added to $10 \mathrm{~mL}$ DMF. The mixture was stirred at $170{ }^{\circ} \mathrm{C}$ under nitrogen. After $20 \mathrm{~h}$, the mixture was cooled to room temperature and $20 \mathrm{~mL}$ ammonia was added. The resulting precipitate was filtered and purified by silica gel column chromatography (dichloromethane/methanol, 50:1). Compound 2 was finally gained as a light-yellow powder with a yield of $4.3 \%$. ${ }^{1} \mathrm{H}$ NMR (400 MHz, DMSO- $\left.d_{6}\right) \delta(\mathrm{ppm}): 11.87(\mathrm{~s}, 1 \mathrm{H}), 8.47$ (s, 2H), 7.55$7.53(\mathrm{~m}, 4 \mathrm{H}), 7.49-7.38(\mathrm{~m}, 6 \mathrm{H}) .{ }^{13} \mathrm{C}$ NMR (100 MHz, DMSO- $\left.d_{6}\right)$ $\delta$ (ppm): 168.31, 155.47, 143.34, 138.38, 133.03, 130.27, 129.91, 128.64, 124.90. ESI-MS spectrometry: $\mathrm{m} / \mathrm{z}$ calculated for $[\mathrm{M}+\mathrm{H}]^{+}$: 352.11; found: 352.11.

\section{Results and discussion}

\subsection{AIE characteristics of 2}

To understand the AIE characteristics of 2, the fluorescence emission of 2 in $\mathrm{H}_{2} \mathrm{O}$ /THF mixed solution with different water fractions $\left(f_{\mathrm{w}}\right.$, from $0 \%$ to $\left.99 \%, \mathrm{v} / \mathrm{v}\right)$ was investigated. As shown in Fig. 1A, along with the increase of $f_{\mathrm{w}}$, the fluorescence intensity of 2 enhanced gradually and reached the maximum when $f_{\mathrm{w}}$ was $99 \%$ (quantum yields enhanced from $0.35 \%$ to $7.46 \%$ ). Normally, water is a poor solvent for organic molecules, which suggested that the fluorescence of 2 in aqueous solution might originate from its aggregated state, i.e., an AIE emission. The aggregation of 2 in aqueous solution was supported by absorption spectra and dynamic light scattering (DLS) measurements. As shown in Fig. 1B, in the absorption spectra of 2 in aqueous solution, a level-off tail in the visible region could be clearly observed, which is believed to be due to the light scattering of aggregate suspensions. ${ }^{6}$ DLS measurements 

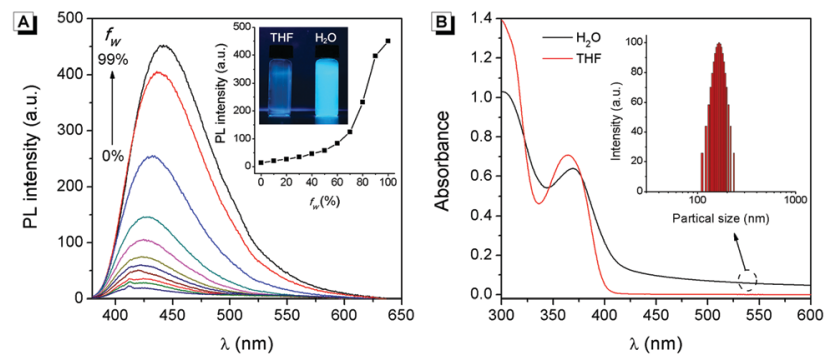

Fig. 1 (A) Fluorescence emission spectra of $50 \mu \mathrm{mol} \mathrm{L} \mathrm{L}^{-1} \mathbf{2}$ in water/THF mixtures with different $f_{\mathrm{w}}$. Inset: Fluorescence intensity of $\mathbf{2}$ at $445 \mathrm{~nm}$ as a function of $f_{\mathrm{w}}$ and fluorescence photograph of 2 in THF and $\mathrm{H}_{2} \mathrm{O}$ (99\% water/THF (v/v) solution). (B) Absorption spectra of $50 \mu \mathrm{mol} \mathrm{L}{ }^{-1} 2$ in THF and $\mathrm{H}_{2} \mathrm{O}$. Inset: DLS results of 2 in $\mathrm{H}_{2} \mathrm{O}$.

indicated that the particle size was around 100 nanometers (Fig. 1B inset).

The origination of the AIE characteristics of 2 was further investigated. First, a single crystal of 2 was grown from methanol/ dichloromethane mixtures via slow solvent evaporation. The structure of the crystal was characterized by X-ray crystallography. As shown in Fig. 2A, the steric hindrances between the two phenyl groups endow 2 with a typical propeller-like structure. The dihedral angles between the phenyl groups and the quinoxaline center were $38.6^{\circ}$ and $42.6^{\circ}$, respectively. This structural feature indicated that the AIE characteristics of 2 might originate from a RIR process: in the dissolved state, the phenyl groups undergo dynamic intramolecular rotations, resulting in an excited state non-radiative transition and fluorescence quenching. In contrast, the rotations of the phenyl groups are limited effectively in the aggregated state. As a result, the radiative transition became the primary pathway for the excited state electrons back to the ground state, along with intense fluorescence emission. ${ }^{7}$ Meanwhile, the minimum distance between the adjacent conjugate moieties of 2 was $3.95 \AA$ (Fig. 2B), suggesting that the stacking interaction in the crystal can be ignored. ${ }^{8}$ The RIR mechanism for the AIE characteristics of 2 was supported by its fluorescence enhancement in solvents with high viscosity. As shown in Fig. S1 (ESI $\dagger$ ), the fluorescence intensity of $\mathbf{2}$ in glycerin is 4 -fold stronger than

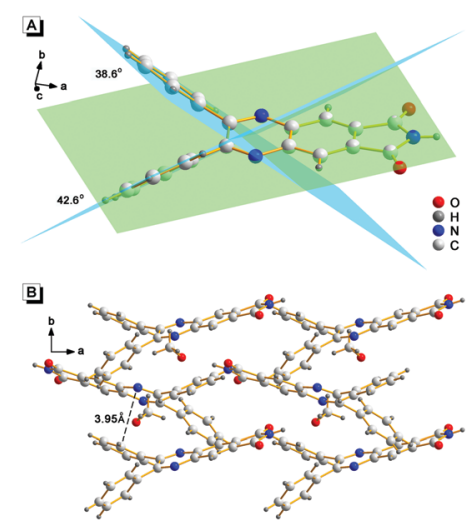

Fig. 2 Crystal structure of 2. (A) The dihedral angles between the conjugate rigid planes. (B) The packing of $\mathbf{2}$ in the crystal and the minimum distance between the adjacent conjugate planes. that in EtOH, which was attributed to the high viscosity solvent that restricted intramolecular rotations.

\subsection{Photo-response performance of 2}

As a typical AIEgen, 2 exhibits weak fluorescence in the dissolved state. Interestingly, upon UV light irradiation, a strong green fluorescence appeared within $5 \mathrm{~s}$ (Fig. 3A and Video S1, ESI $\dagger$ ). To understand this photo-response process, the absorption spectra of 2 upon UV light irradiation were recorded. As shown in Fig. 3B, three isobestic points could clearly be observed, suggesting the formation of new compounds after UV light irradiation.

More evidence for the formation of new compounds was obtained from HPLC analysis. As shown in Fig. 3C, in a mobile phase of $\mathrm{MeOH}$, compound 2 exhibits a peak at a retention time of 3.6 min. After UV light irradiation, the peak of compound 2 decreased gradually, while a new peak with a retention time of 3.2 min appeared. These results confirmed that new compounds were formed after light irradiation. To understand the photo-response mechanism of 2, ESI-mass spectra of the system before and after light irradiation were recorded. Interestingly, both of them exhibited a peak with a charge-to-mass ratio of $352.11\left([2+\mathrm{H}]^{+}, m / z\right.$ calcd 352.11), which suggested that there might be a photo-induced rearrangement reaction for compound 2. According to the reports, photoclick cycloaddition reactions could happen in some AIEgens which have adjacent aromatic rings combined with electron-withdrawing groups. ${ }^{9}$ As shown in Fig. 3D, compound 2 has these structural features. Thus, a possible photo-response mechanism of 2 was proposed based on the above results: upon UV light irradiation, 3 was produced through a photoclick cycloaddition reaction, and protons in the adjacent phenyl moieties transferred to the quinoxaline moiety. 3 has a large conjugate rigid plane structure and exhibits strong green fluorescence in the dissolved state.
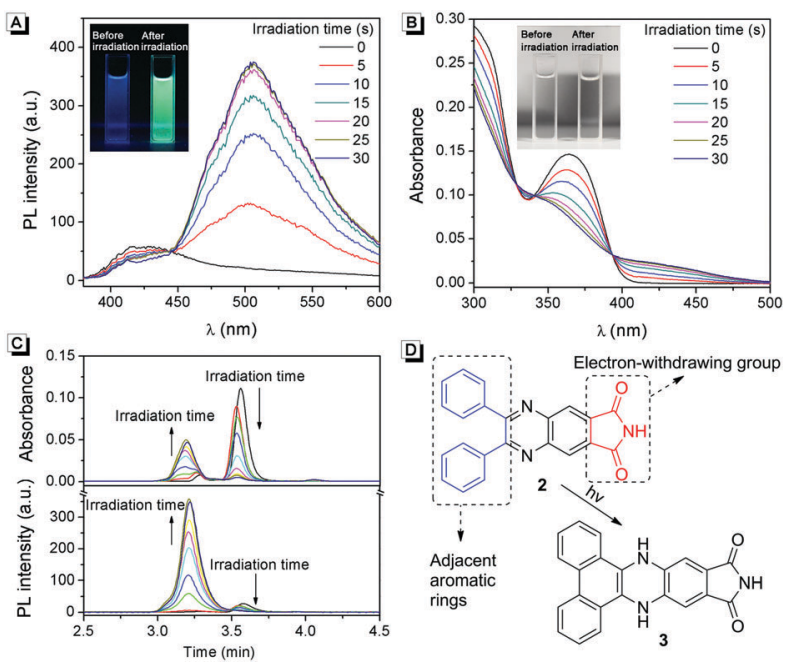

Fig. 3 (A) Fluorescence spectra and (B) absorption spectra of $10 \mu \mathrm{mol} \mathrm{L}^{-1}$ 2 in THF before and after UV light irradiation. (C) HPLC analysis of the photoconversion of $10 \mu \mathrm{mol} \mathrm{L} \mathrm{L}^{-1} \mathbf{2}$ to $\mathbf{3}$ under UV light irradiation for different times. (D) Proposed mechanism for the photo-response performance of $\mathbf{2}$ upon UV light irradiation. 

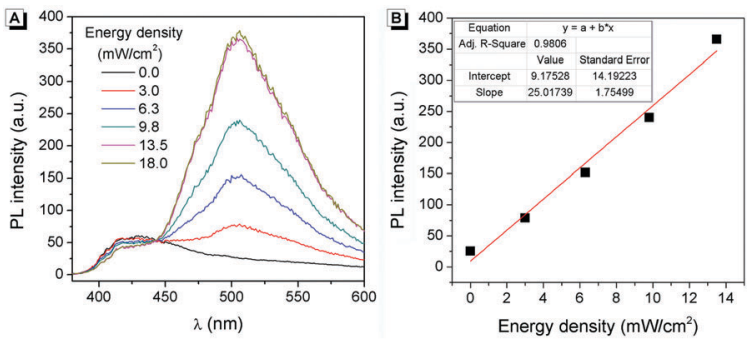

Fig. 4 (A) Fluorescence spectra of $10 \mu \mathrm{mol} \mathrm{L}^{-1}$ of 2 in THF irradiated by $365 \mathrm{~nm}$ light with different irradiation intensities for $5 \mathrm{~s}$. (B) Fluorescence intensity at $506 \mathrm{~nm}$ as a function of irradiation intensity.

The effect of the light irradiation wavelength on the photoresponse reaction was further investigated. As shown in Table S1 (ESI $\dagger$ ), light with different wavelengths was used to irradiate the sample, and only UV light $(<400 \mathrm{~nm})$ can promote the photo-response reaction. This wavelength range was fitted well with the absorption spectrum of 2 because there was no absorption beyond $400 \mathrm{~nm}$ (Fig. 1B). Then $365 \mathrm{~nm}$ UV light was used to understand the influence of light intensity on the photo-response reaction. As shown in Fig. 4A, after being irradiated by $365 \mathrm{~nm}$ UV light with different light intensities for $5 \mathrm{~s}$, different fluorescence intensities can be observed. Stronger light led to more intense fluorescence and a good linear relationship was achieved (Fig. 4B). When the light intensity was higher than $13.5 \mathrm{~mW} \mathrm{~cm}{ }^{-2}$, the fluorescence intensity reached saturation after $5 \mathrm{~s}$ of irradiation. These results suggested that compound 2 can be used as a sensitive UV strength sensor.

Furthermore, the photo-response property of 2 in the solid state was investigated. The fluorescence and absorption spectra of 2 in polyethylene oxide (PEO) before and after light irradiation are shown in Fig. S2 (ESI $\dagger$ ). As can be seen, a ratiometric absorption change and a turn-on fluorescence change can be observed. These features indicate that $\mathbf{2}$ is capable of serving as a material for photo-printing. As shown in Fig. 5 and Video S2 (ESI $\dagger$ ), letters are successfully recorded on 2 in polyethylene oxide after UV light irradiation. Under day light, the letters were very faint and hard to recognize. In contrast, the letters were clearly visualized under UV light. This tremendous contrast endows 2 with great potential for application in anticounterfeiting materials.

\section{3 $\mathrm{Hg}$ (II) sensing ability of 2}

$\mathrm{Hg}$ (II) is one of the most toxic metal ions for human health, and is widespread in environmental samples. ${ }^{10}$ The detection of $\mathrm{Hg}$ (II) has long been a great concern. According to the reports,

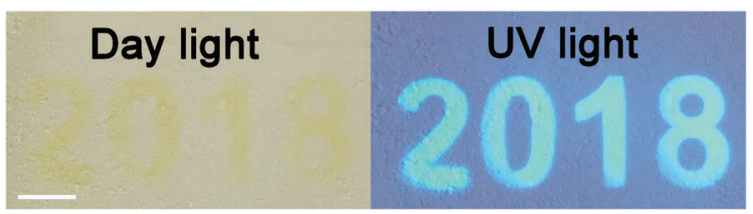

Fig. 5 Photographic images of $\mathbf{2}$ in PEO. The letters were generated upon irradiation at $365 \mathrm{~nm}$. The scale bar is $2 \mathrm{~mm}$.
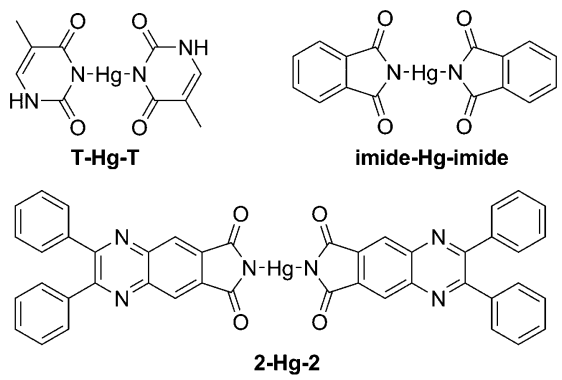

Scheme 2 The structures of the T-Hg-T complex, the imide-Hg-imide complex and the $\mathbf{2}-\mathbf{H g}-\mathbf{2}$ complex.

$\mathrm{Hg}$ (II) can efficiently bind with two $\mathrm{T}$ bases (thymine) to form a stable neutral T-Hg-T complex (Scheme 2). Guided by this theory, many fluorescence probes containing thymine moieties have been developed for the detection of $\mathrm{Hg}(\mathrm{III}){ }^{11}$ Besides thymine, other organic molecules with $N$-unsubstituted cyclic imides can also highly selectively bind to $\mathrm{Hg}(\mathrm{II}){ }^{12}$ Thus, as a luminogen with an $N$-unsubstituted cyclic imide moiety, the fluorescence response of 2 to $\mathrm{Hg}$ (II) was investigated.

As shown in Fig. 6A, the fluorescence intensity of 2 decreased gradually upon the addition of $\mathrm{Hg}$ (II) and reached the minimum when more than 0.5 equiv. of $\mathrm{Hg}$ (II) was added. When excess cysteine (Cys, a classic chelator for $\mathrm{Hg}(\mathrm{II})^{13}$ ) was added to the solution, the fluorescence intensity restored immediately (Fig. S3, ESI $\dagger$ ). As shown in Fig. 6B, 2 exhibited a linear range of $0.0-2.0 \mu \mathrm{mol} \mathrm{L}{ }^{-1} \mathrm{Hg}$ (II) with a correlation coefficient of $R_{2}=$ 0.990. Interestingly, there was nearly no fluorescence emission change upon the addition of other common metal ions $(\mathrm{Na}(\mathrm{I}), \mathrm{K}(\mathrm{I})$, $\mathrm{Mg}(\mathrm{II}), \mathrm{Ca}(\mathrm{II}), \mathrm{Ba}(\mathrm{II}), \mathrm{Al}(\mathrm{III}), \mathrm{Cr}(\mathrm{III}), \mathrm{Mn}$ (II), $\mathrm{Fe}(\mathrm{II}), \mathrm{Fe}(\mathrm{III}), \mathrm{Co}(\mathrm{II}), \mathrm{Ni}(\mathrm{II})$, $\mathrm{Cu}(\mathrm{II}), \mathrm{Ag}(\mathrm{I}), \mathrm{Zn}(\mathrm{II}), \mathrm{Cd}(\mathrm{II})$, and $\mathrm{Pb}(\mathrm{II}))$, which indicated that 2 has
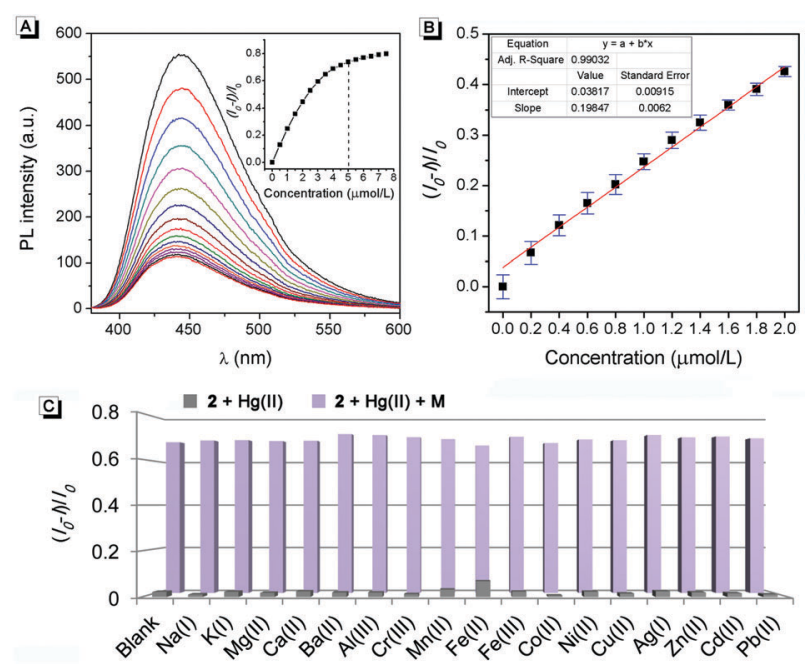

Fig. 6 (A) Fluorescence spectra of 2 upon the addition of $\mathrm{Hg}($ (I). Inset: The fluorescence intensity at $445 \mathrm{~nm}$ as a function of the $\mathrm{Hg}(\mathrm{II})$ concentration. (B) Calibration curve for the emission of $\mathbf{2}$ with increasing concentrations of $\mathrm{Hg}(\mathrm{II}$ ). (C) Fluorescence intensity at $445 \mathrm{~nm}$ in the presence of 0.5 equiv. of different metal ions. Conditions: the concentration of $\mathbf{2}$ was $10 \mu \mathrm{mol} \mathrm{L}$, $99 \%$ water/DMSO $(\mathrm{v} / \mathrm{v})$ at $\mathrm{pH} 7.0$ controlled by $10 \mathrm{mmol} \mathrm{L}^{-1}$ Tris solution. 

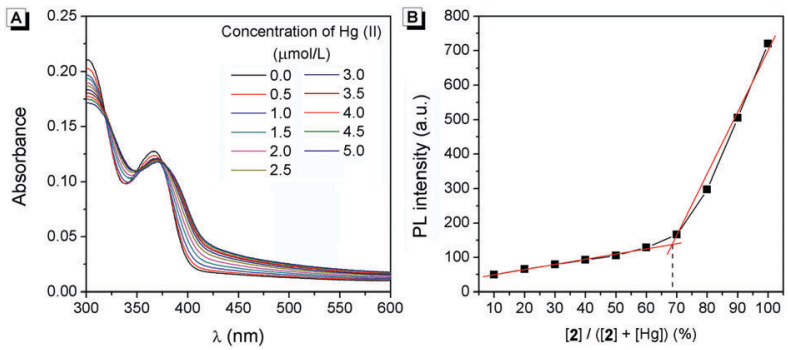

Fig. 7 (A) Absorption spectra of $10 \mu \mathrm{mol} \mathrm{L}^{-1} \mathbf{2}$ upon the addition of $\mathrm{Hg}(\mathrm{II}$ ). (B) Job's plot data for evaluating the stoichiometry of the $\mathbf{2}-\mathbf{H g} \mathbf{- 2}$ complex. The total concentration of 2 and $\mathrm{Hg}\left(\right.$ (I) was kept at $20 \mu \mathrm{mol} \mathrm{L}^{-1}$. $99 \%$ water/ DMSO (v/v) at pH 7.0 controlled by $10 \mathrm{mmol} \mathrm{L}^{-1}$ Tris solution was used. Excitation and emission were performed at $368 \mathrm{~nm}$ and $445 \mathrm{~nm}$, respectively.

excellent selectivity and provided more anti-interference capability to $\mathrm{Hg}$ (II) than other metal ions (Fig. 6C). These results suggested that 2 could be used as a selective chemosensor for the detection of $\mathrm{Hg}$ (II).

The mechanism of the response for 2 to $\mathrm{Hg}$ (II) was further investigated (Scheme 2). Firstly, three isobestic points could clearly be observed in the absorption of 2 upon the addition of $\mathrm{Hg}$ (II), indicating the formation of a complex between 2 and $\mathrm{Hg}$ (II) (Fig. 7A). Secondly, Job's plot analysis was carried out to confirm the stoichiometry of $\mathbf{2 - H g}-\mathbf{2}$. The result indicated that the binding ratio between 2 and $\mathrm{Hg}$ (II) was 2:1 (Fig. 7B). Moreover, the binding site of 2 to $\mathrm{Hg}$ (II) was verified by ${ }^{1} \mathrm{H}$-NMR spectra (Fig. 8). Before the addition of $\mathrm{Hg}$ (II), the proton of the $o$-phthalimide moiety (proton a) could well be assigned. After the addition of $\mathrm{Hg}$ (II) into the mixture, the peak of "proton a" reduced significantly while other peaks showed almost no change, suggesting that 2 bound $\mathrm{Hg}$ (II) with its imide group.

\section{4 pH sensing ability of 2}

According to the reports, hydrogen in the $o$-phthalimide moiety was very active, which could be removed under alkaline conditions. ${ }^{14}$ Therefore, the fluorescence of 2 in aqueous

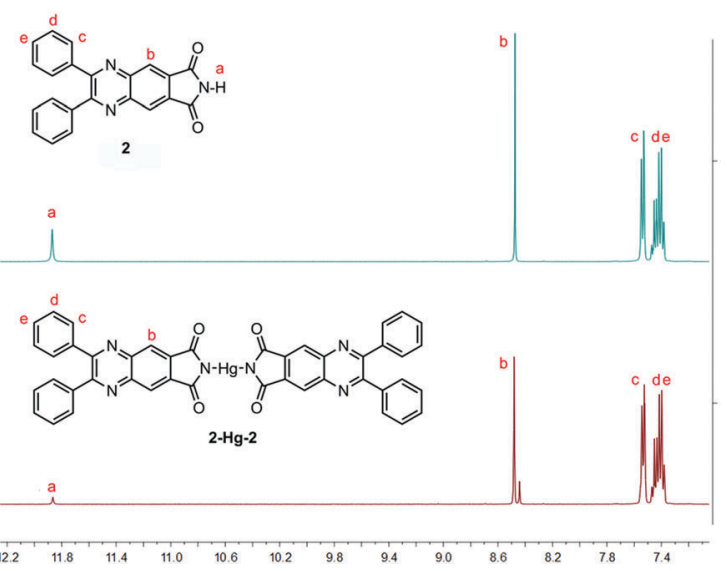

Fig. $8{ }^{1} \mathrm{H}-\mathrm{NMR}$ spectra of $\mathbf{2}$ in DMSO- $d_{6}$ before (up) and after (down) the addition of 0.5 equiv. $\mathrm{Hg}(\mathrm{II})$.
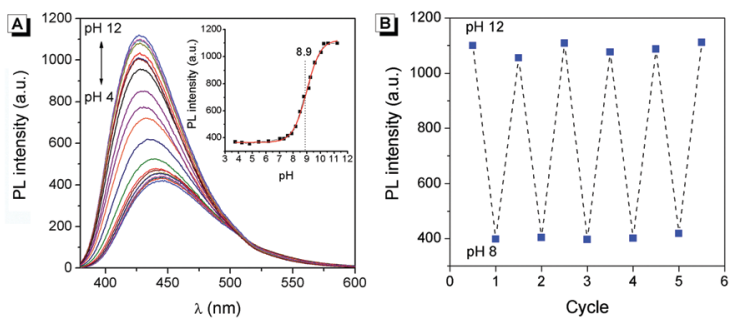

Fig. 9 (A) Fluorescence spectra of $\mathbf{2}$ in aqueous solution with different $\mathrm{pH}$ values. Inset: The fluorescence intensity at $426 \mathrm{~nm}$ as a function of $\mathrm{pH}$. (B) Reversible fluorescence changes of 2 at $426 \mathrm{~nm}$ by adjusting its solution to $\mathrm{pH} 8$ and $\mathrm{pH} 12$ repeatedly.

solutions with different pHs was investigated. As shown in Fig. 9A, along with the increase of $\mathrm{pH}$, the fluorescence intensity of 2 enhanced gradually and the emission wavelength blueshifted from $445 \mathrm{~nm}$ to $426 \mathrm{~nm}$. The titration curve as shown in the Fig. 9A inset indicated a jump ranging from about $\mathrm{pH} 8$ to $\mathrm{pH} 10$, and an acid dissociation constant $\left(\mathrm{p} K_{\mathrm{a}}\right)$ of 8.9 was obtained by nonlinear fitting $\left(R_{2}=0.997\right)$. Meanwhile, the fatigue resistance of 2 to the $\mathrm{pH}$ change was investigated. As can be seen in Fig. 9B, the fluorescence intensity of 2 stayed almost constant without apparent degradation when the $\mathrm{pH}$ of the solution was switched back and forth between 8.0 and 12.0 5 times. These results suggested that 2 could be used as a reversible fluorescent chemosensor for $\mathrm{pH}$ sensing.

To understand the $\mathrm{pH}$ response mechanism of 2 , the ${ }^{1} \mathrm{H}-\mathrm{NMR}$ spectrum of 2 in the absence and presence of alkali was recorded. As shown in Fig. 10, the peak of the proton in the $o$-phthalimide moiety (proton a) disappeared after the addition of triethylamine (TFA). When excess trifluoroacetic acid (TEA) was further added to the solution, the peak of "proton a" recovered. These results provide powerful evidence for the deprotonation and protonation of 2 at different $\mathrm{pH}$ values. Furthermore, the absorption spectra and particle size distribution of 2 at different pHs were investigated. As shown in Fig. S4 (ESI $\dagger$ ), the shapes of the absorption spectra of 2 at different $\mathrm{pHs}$ were very similar, while level-off tails in the visible region disappeared when the $\mathrm{pH}$ was higher than 9, indicating that

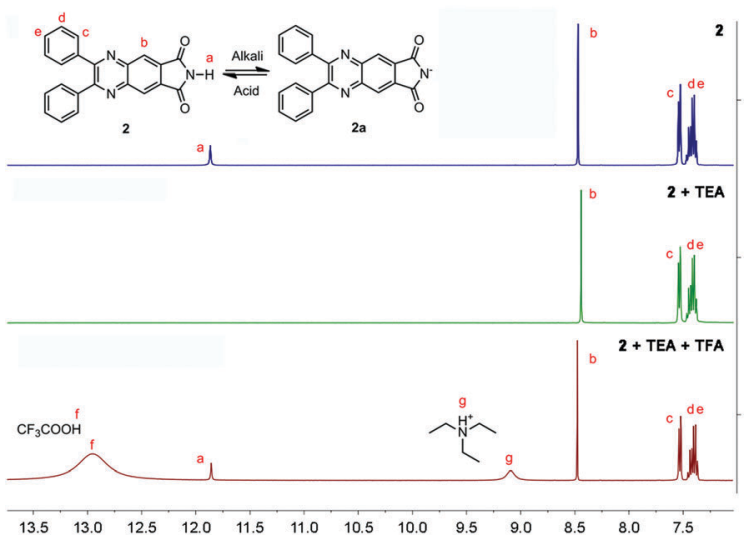

Fig. $10{ }^{1} \mathrm{H}$-NMR spectra of 2 before and after the addition of excess TEA and TFA. 
the aggregation of 2 was dissolved. Meanwhile, in the DLS test no particle could be observed for 2 at $\mathrm{pH} 12$, which also confirmed the good solubility of 2a. According to the above results, the proposed response mechanism of 2 to $\mathrm{pH}$ is obtained: when the $\mathrm{pH}$ was lower than 8,2 existed in the form of a neutral molecule, exhibiting AIE fluorescence around $445 \mathrm{~nm}$; when the $\mathrm{pH}$ was higher than 10, 2 underwent deprotonation, producing $\mathbf{2 a}$ with stronger fluorescence around $426 \mathrm{~nm}$. The negative charge of $\mathbf{2 a}$ endows it with good solubility in aqueous solution.

\section{Conclusions}

In conclusion, an $o$-phthalimide-based AIE molecule of 2 was developed, which can be used in multifunctional sensing applications for UV light, $\mathrm{Hg}$ (II) and $\mathrm{pH}$ value. Mechanism studies showed that the AIE property of 2 originated from a typical RIR process. Upon UV light irradiation, a photoclick cycloaddition reaction occurred in 2 , producing an isomer with a large conjugate rigid plane structure and intense green fluorescence. This feature makes 2 suitable for the detection of UV light. The $o$-phthalimide moiety plays a crucial role in the detection of $\mathbf{H g}$ (II) and the $\mathrm{pH}$ value. By forming a $\mathbf{2 - \mathbf { H g } - \mathbf { 2 }}$ complex with the $o$-phthalimide moiety, 2 exhibited a highly selective fluorescence response to $\mathrm{Hg}$ (II) with a linear range of 0.0-2.0 $\mu \mathrm{mol} \mathrm{L}^{-1}$. A deprotonation process takes place in the $o$-phthalimide moiety of 2 at a high $\mathrm{pH}$ value, resulting in an increase of fluorescence. Besides these sensing applications, 2 was also successfully used in photo-printing and anticounterfeiting materials.

\section{Conflicts of interest}

There are no conflicts to declare.

\section{Acknowledgements}

This research was supported by the National Natural Science Foundation of China (No. 21501150, 51502079, and 21671174), the Scientific Research Foundation for Young Teacher of Zhengzhou University (51099075), the Fundamental Research Funds for the Henan Provincial Colleges and Universities (2015QNJH09), the Science Foundation of Henan University of Technology (2015BS004), the Science and Technology Key Project of Henan Education Department (18A150026), and Funding of Henan Key Laboratory of Cereal Resource Transformation and Utilization (PL2017006).

\section{Notes and references}

1 (a) L. Chen, G. Lin, H. Peng, S. Ding, W. Luo, R. Hu, S. Chen, F. Huang, A. Qin, Z. Zhao and B. Z. Tang, Mater. Chem. Front., 2017, 1, 176-180; (b) M. Z. Chen, N. S. Moily, J. L. Bridgford, R. J. Wood, M. Radwan, T. A. Smith, Z. Song, B. Z. Tang, L. Tilley and X. Xu, Nat. Commun.,
2017, 8, 474; (c) J. Qian and B. Z. Tang, Chem, 2017, 3, 56-91; (d) J. Yang, Y. T. Gao, T. Jiang, W. Liu, C. C. Liu, N. N. Lu, B. Li, J. Mei, Q. Peng and J. L. Hua, Mater. Chem. Front., 2017, 1, 1396-1405; (e) Y. Zheng, X. K. Zheng, Y. X. Xiang and A. J. Tong, Chem. Commun., 2017, 53, 11130-11133; (f) C. Wang and Z. Li, Mater. Chem. Front., 2017, 1, 2174-2194; (g) J. Yang, L. Li, Z. Ren, Q. Peng, S. Ye, Q. Li and Z. Li, Mater. Chem. Front., 2017, 1, 91-99; (h) Y. C. Chen, W. J. Zhang, Z. Zhao, Y. J. Cai, J. Y. Gong, R. T. K. Kwok, J. W. Y. Lam, H. H. Y. Sung, L. D. Williams and B. Z. Tang, Angew. Chem., Int. Ed., 2018, 57, 5011-5015; (i) X. W. He, Z. Zhao, L. H. Xiong, P. F. Gao, C. Peng, R. S. Li, Y. Xiong, Z. Li, H. H. Sung, I. D. Williams, R. T. K. Kwok, J. W. Y. Lam, C. Z. Huang, N. Ma and B. Z. Tang, J. Am. Chem. Soc., 2018, 140, 6904-6911; ( $j$ ) H. J. Liu, J. J. Zeng, J. J. Guo, H. Nie, Z. J. Zhao and B. Z. Tang, Angew. Chem., Int. Ed., 2018, 57, 1-6; (k) G. Niu, R. Y. Zhang, J. P. C. Kwong, J. W. Y. Lam, C. P. Chen, J. G. Wang, Y. C. Chen, X. Feng, R. T. K. Kwok, H. H. Y. Sung, L. D. Williams, M. R. J. Elsegood, J. N. Qu, C. Ma, K. S. Wong, X. Q. Yu and B. Z. Tang, Chem. Mater., 2018, 30, 4778-4787; (l) P. Wei, J. X. Zhang, Z. Zhao, Y. Chen, X. He, M. Chen, J. Gong, H. H. Sung, I. D. Williams, J. W. Y. Lam and B. Z. Tang, J. Am. Chem. Soc., 2018, 140, 1966-1975; (m) S. Xie, A. Y. H. Wong, R. T. K. Kwok, Y. Li, H. F. Su, J. W. Y. Lam, S. J. Chen and B. Z. Tang, Angew. Chem., Int. Ed., 2018, 57, 5750-5753.

2 (a) J. D. Luo, Z. L. Xie, J. W. Y. Lam, L. Cheng, H. Y. Chen, C. F. Qiu, H. S. Kwok, X. W. Zhan, Y. Q. Liu, D. B. Zhu and B. Z. Tang, Chem. Commun., 2001, 1740-1741; (b) Y. N. Hong, J. W. Y. Lam and B. Z. Tang, Chem. Soc. Rev., 2011, 40, 5361-5388; (c) R. R. Hu, N. L. C. Leung and B. Z. Tang, Chem. Soc. Rev., 2014, 43, 4494-4562; (d) J. Zhang, H. Kang, N. Li, S. Zhou, H. Sun, S. Yin, N. Zhao and B. Z. Tang, Chem. Sci., 2017, 8, 577-582; (e) L. Ma, X. Feng, S. Wang and B. Wang, Mater. Chem. Front., 2017, 1, 2474-2486.

3 (a) D. Ding, K. Li, B. Liu and B. Z. Tang, Acc. Chem. Res., 2013, 46, 2441-2453; (b) R. T. K. Kwok, C. W. T. Leung, J. W. Y. Lam and B. Z. Tang, Chem. Soc. Rev., 2015, 44, 4228-4238; (c) M. Gao and B. Z. Tang, ACS Sens., 2017, 2, 1382-1399; (d) J. Mei, Y. H. Huang and H. Tian, ACS Appl. Mater. Interfaces, 2017, 10, 12217-12261; (e) J. Shi, Y. Li, Q. Li and Z. Li, ACS Appl. Mater. Interfaces, 2018, 10, 12278-12294.

4 (a) P. S. Song, X. T. Chen, Y. Xiang, L. Huang, Z. J. Zhou, R. R. Wei and A. J. Tong, J. Mater. Chem., 2011, 21, 13470-13475; (b) Y. X. Guo, X. Feng, T. Y. Han, S. Wang, Z. G. Lin, Y. P. Dong and B. Wang, J. Am. Chem. Soc., 2014, 136, 15485-15488; (c) Q. Feng, Y. Y. Li, K. Li, J. Y. Lu, J. M. Wang, P. Y. Fan, D. K. Li, D. M. Wu and H. W. Hou, ChemistrySelect, 2017, 2, 3158-3162; (d) N. Zhao, Q. Gong, R. X. Zhang, J. Yang, Z. Y. Huang, N. Li and B. Z. Tang, J. Mater. Chem. C, 2015, 3, 8397-8402; (e) R. X. Zhang, P. F. Li, W. J. Zhang, N. Li and N. Zhao, J. Mater. Chem. C, 2016, 4, 10479-10485; ( $f$ ) Y. H. Cheng, J. G. Wang, Z. J. Qiu, X. Y. Zheng, N. L. C. Leung, J. W. Y. Lam and B. Z. Tang, Adv. Mater., 2017, 29, 1703900; (g) P. Zhang, X. Nie, M. Gao, 
F. Zeng, A. Qin, S. Wu and B. Z. Tang, Mater. Chem. Front., 2017, 1, 838-845; (h) L. Y. Chen, H. Oh, D. Wu, M. H. Kim and J. Y. Yoon, Chem. Commun., 2018, 54, 2276-2279; (i) N. Li, Y. Y. Liu, Y. Li, J. B. Zhuang, R. R. Cui, Q. Gong, N. Zhao and B. Z. Tang, ACS Appl. Mater. Interfaces, 2018, 10, 24249-24257; ( j) Z. J. Ruan, Y. R. Shan, Y. B. Gong, C. Wang, F. B. Ye, Q. Yu, Z. Q. Liang and Z. Li, J. Mater. Chem. C, 2018, 6, 773-780; (k) F. Xia, Y. Cheng, J. Dai, C. L. Sun, R. Liu, T. Y. Zhai and X. D. Lou, Angew. Chem., Int. Ed., 2018, 57, 3123-3127.

5 (a) W. X. Tang, Y. Xiang and A. J. Tong, J. Org. Chem., 2009, 74, 2163-2166; (b) K. Li, Y. Y. Liu, Y. Y. Li, Q. Feng, H. Hou and B. Z. Tang, Chem. Sci., 2017, 8, 7258-7267; (c) M. Chen, L. Z. Li, H. Nie, J. Q. Tong, L. L. Yan, B. Xu, J. Z. Sun, W. J. Tian, Z. J. Zhao, A. J. Qin and B. Z. Tang, Chem. Sci., 2015, 6, 1932-1937; (d) J. Mei, N. L. C. Leung, R. T. K. Kwok, J. W. Y. Lam and B. Z. Tang, Chem. Rev., 2015, 115, 11718-11940; (e) Z. J. Zhao, B. R. He and B. Z. Tang, Chem. Sci., 2015, 6, 5347-5365; $(f)$ Q. Feng, Y. Y. Li, L. L. Wang, C. Li, J. M. Wang, Y. Y. Liu, K. Li and H. W. Hou, Chem. Commun., 2016, 52, 3123-3126; $(g)$ K. Li, Q. Feng, G. Niu, W. Zhang, Y. Li, M. Kang, K. Xu, J. He, H. Hou and B. Z. Tang, ACS Sens., 2018, 3, 920-928.

6 J. W. Chen, C. C. W. Law, J. W. Y. Lam, Y. P. Dong, S. M. F. Lo, I. D. Williams, D. Zhu and B. Z. Tang, Chem. Mater., 2003, 15, 1535-1546.

7 (a) A. J. Qin, J. W. Y. Lam, F. Mahtab, C. K. W. Jim, L. Tang, J. Z. Sun, H. H. Y. Sung, I. D. Williams and B. Z. Tang, Appl. Phys. Lett., 2009, 94, 253308; (b) J. Mei, Y. N. Hong, J. W. Y. Lam, A. J. Qin, Y. H. Tang and B. Z. Tang, Adv. Mater., 2014, 26, 5429-5479.

8 (a) C. A. Hunter and J. K. M. Sanders, J. Am. Chem. Soc., 1990, 112, 5525-5534; (b) M. O. Sinnokrot, E. F. Valeev and C. D. Sherrill, J. Am. Chem. Soc., 2002, 124, 10887-10893; (c) L. L. Wang, Y. Y. Li, X. J. You, K. Xu, Q. Feng, J. M. Wang, Y. Y. Liu, K. Li and H. W. Hou, J. Mater. Chem. C, 2016, 5, 65-72.

9 (a) M. Irie, T. Fukaminato, K. Matsuda and S. Kobatake, Chem. Rev., 2014, 114, 12174-12277; (b) X. G. Gu, E. G. Zhao,
J. W. Y. Lam, Q. Peng, Y. J. Xie, Y. L. Zhang, K. S. Wong, H. H. Sung, I. D. Williams and B. Z. Tang, Adv. Mater., 2015, 27, 7093-7100; (c) X. G. Gu, E. G. Zhao, T. Zhao, M. M. Kang, C. Gui, J. W. Y. Lam, S. W. Du, M. M. T. Loy and B. Z. Tang, Adv. Mater., 2016, 28, 5064-5071; (d) D. P. Ou, T. Yu, Z. Y. Yang, T. G. Luan, Z. Mao, Y. Zhang, S. W. Liu, J. R. Xu, Z. G. Chi and M. R. Bryce, Chem. Sci., 2016, 7; (e) T. Yu, D. P. Ou, L. Y. Wang, S. Z. Zheng, Z. Y. Yang, Y. Zhang, Z. G. Chi, S. W. Liu, J. R. Xu and M. P. Aldred, Mater. Chem. Front., 2017, 1, 1900-1904.

10 (a) E. M. Nolan and S. J. Lippard, Chem. Rev., 2008, 108, 3443-3480; (b) H. N. Kim, W. X. Ren, J. S. Kim and J. Yoon, Chem. Soc. Rev., 2012, 41, 3210-3244; (c) P. A. Ariya, M. Amyot, A. Dastoor, D. Deeds, A. Feinberg, G. Kos, A. Poulain, A. Ryjkov, K. Semeniuk and M. Subir, Chem. Rev., 2015, 115, 3760-3802.

11 (a) Y. Miyake, H. Togashi, M. Tashiro, H. Yamaguchi, S. Oda, M. Kudo, Y. Tanaka, Y. Kondo, R. Sawa and T. Fujimoto, J. Am. Chem. Soc., 2006, 128, 2172-2173; (b) S. Maiti, C. Pezzato, G. S. Martin and L. J. Prins, J. Am. Chem. Soc., 2014, 136, 11288-11291; (c) B. Lippert and P. J. S. Miguel, Acc. Chem. Res., 2016, 1537-1545; (d) O. P. Schmidt, G. Mata and N. W. Luedtke, J. Am. Chem. Soc., 2016, 138, 14733-14739; (e) X. M. Xu, R. Z. Hou, P. C. Gao, M. Miao, X. D. Lou, B. F. Liu and F. Xi, Anal. Chem., 2016, 88, 2386-2391.

12 (a) I. Okamoto, K. Iwamoto, Y. Watanabe, Y. Miyake and A. Ono, Angew. Chem., Int. Ed., 2009, 48, 1648-1651; (b) C.-L. Fang, J. Zhou, X.-J. Liu, Z.-H. Cao and D.-H. Shangguan, Dalton Trans., 2011, 40, 899-903; (c) S. Mandal, M. Hebenbrock and J. Müller, Angew. Chem., Int. Ed., 2016, 55, 15520-15523.

13 (a) S. M. Jia, X. F. Liu, P. Li, D. M. Kong and H. X. Shen, Biosens. Bioelectron., 2011, 27, 148-152; (b) K. Xu, Y. Li, Y. Si, Y. He, J. Ma, J. He, H. Hou and K. Li, J. Lumin., 2018, 204, 182-188.

14 M. S. Gibson and R. W. Bradshaw, Angew. Chem., Int. Ed., 1968, 7, 919-930. 